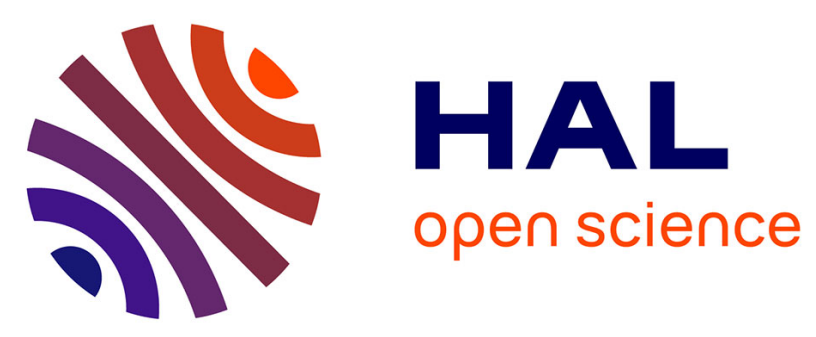

\title{
Social deprivation is associated with poor kidney transplantation outcome in children
}

Benedicte Driollet, F. Bayer, V. Chatelet, M. A. Macher, R. Salomon, B. Ranchin, G. Roussey, A. Lahoche, F. Garaix, S. Decramer, et al.

\section{To cite this version:}

Benedicte Driollet, F. Bayer, V. Chatelet, M. A. Macher, R. Salomon, et al.. Social deprivation is associated with poor kidney transplantation outcome in children. Kidney International, 2019, 96 (3), pp.769-776. 10.1016/j.kint.2019.05.011 . hal-03211514

\section{HAL Id: hal-03211514 \\ https://hal.science/hal-03211514}

Submitted on 20 Dec 2021

HAL is a multi-disciplinary open access archive for the deposit and dissemination of scientific research documents, whether they are published or not. The documents may come from teaching and research institutions in France or abroad, or from public or private research centers.
L'archive ouverte pluridisciplinaire HAL, est destinée au dépôt et à la diffusion de documents scientifiques de niveau recherche, publiés ou non, émanant des établissements d'enseignement et de recherche français ou étrangers, des laboratoires publics ou privés.

\section{다)(1) $(5$}

Distributed under a Creative Commons Attribution - NonCommerciall 4.0 International 
[QUERY TO AUTHOR: title and abstract rewritten by Editorial Office - not subject to change]

\section{Social deprivation is associated with poor kidney transplantation outcome in children.}

\section{Authors}

Bénédicte Driollet ${ }^{1}$, MSc; Florian Bayer ${ }^{2}, \mathrm{MSc}$; Valérie Chatelet $^{3}$, MD; Marie-Alice Macher ${ }^{2,4}, \mathrm{MD}$; Rémi Salomon ${ }^{5}, \mathrm{MD}$, PhD; Bruno Ranchin ${ }^{6}, \mathrm{MD} ;$ Gwenaelle Roussey ${ }^{7}, \mathrm{MD}$; Annie Lahoche ${ }^{8}, \mathrm{MD}$; Florentine Garaix$^{9}, \mathrm{MD}$; Stéphane Decramer ${ }^{10}, \mathrm{MD}$, PhD; Elodie Mérieau ${ }^{11}, \mathrm{MD}$; Marc Fila ${ }^{12}, \mathrm{MD}$, PhD; Ariane Zaloszyc $^{13}, \mathrm{MD}$, PhD; Georges Deschênes ${ }^{4}, \mathrm{MD}$, PhD; Linda Valeri ${ }^{14}, \mathrm{PhD}$; Ludivine Launay ${ }^{15}, \mathrm{MSc}$; Cécile Couchoud ${ }^{2}, \mathrm{MD}$, PhD; Karen Leffondré ${ }^{1,16 \#}, \mathrm{PhD}$; Jérôme Harambat ${ }^{1,16,17 \#}, \mathrm{MD}, \mathrm{PhD}$

\section{Affiliations}

${ }^{1}$ University of Bordeaux, ISPED, Centre INSERM U1219-Bordeaux Population Health Research, Bordeaux, France

${ }^{2}$ Agence de la Biomédecine, La Plaine-Saint Denis, France

${ }^{3}$ Department of Nephrology, Caen University Hospital, Caen, France

${ }^{4}$ Pediatric Nephrology Unit, Robert Debré Hospital, Centre de Référence Maladies rénales rares Marhea, APHP, Paris, France

${ }^{5}$ Pediatric Nephrology Unit, Necker Enfants-Malades Hospital, Centre de Référence Maladies rénales rares Marhea, APHP, Paris Descartes University, Paris, France

${ }^{6}$ Pediatric Nephrology Unit, Femme-Mère-Enfant Hospital, Lyon University Hospital, Centre de Référence Maladies rénales rares Nephrogones, Bron, France

${ }^{7}$ France Pediatric Nephrology Unit, Femme-Enfant-Adolescent Hospital, Nantes University Hospital, Nantes, France

${ }^{8}$ Pediatric Nephrology Unit, Jeanne de Flandre Hospital, Lille University Hospital, Lille

${ }^{9}$ Pediatric Nephrology Unit, Timone-Enfants Hospital, Marseille University Hospital, Marseille, France

${ }^{10}$ Pediatric Nephrology Unit, Children's Hospital, Toulouse University Hospital, Centre de Référence Maladies rénales rares Sorare, Toulouse, France

${ }^{11}$ Pediatric Nephrology Unit, Clocheville Hospital, Tours University Hospital, Tours, France

${ }^{12}$ Pediatric Nephrology Unit, Arnaud de Villeneuve Hospital, Montpellier University Hospital, Centre de Référence Maladies rénales rares Sorare, Montpellier, France

${ }^{13}$ Pediatric Nephrology Unit, Hautepierre Hospital, Strasbourg University Hospital, Strasbourg, France

${ }^{14}$ Department of Psychiatry, Harvard Medical School and McLean Hospital, Boston, MA, USA

${ }^{15}$ INSERM-UCN U1086 Anticipe, Centre de Lutte contre le Cancer François Baclesse, Caen, France

${ }^{16}$ INSERM, Clinical Investigation Center-Clinical Epidemiology-CIC-1401, Bordeaux, France

17 Pediatric Nephrology Unit, Pellegrin-Enfants Hospital, Bordeaux University Hospital, Centre de Référence Maladies rénales rares Sorare, Bordeaux, France

\# These authors contributed equally to this work

Corresponding author: benedicte.driollet@u-bordeaux.fr or jerome.harambat@chu-bordeaux.fr 


\begin{abstract}
Socioeconomic status is an important determinant of health. Its impact on kidney transplantation outcome has been studied among adults but data in children are scarce, especially in Europe. Here, we investigate the association between the level of social deprivation (determined by the continuous score European Deprivation Index) and graft failure risk in pediatric kidney transplant recipients. All patients listed under 18 years of age who received a first kidney transplant between 2002 and 2014 in France were included. Of 1050 kidney transplant recipients (males 59\%, median age at transplantation 13.2 years, preemptive transplantation 23\%), 211 graft failures occurred within a median follow up of 5.9 years. Thirty seven percent of these patients belong to the most deprived quintile, suggesting that deprivation is more frequent in pediatric patients with end stage kidney disease than in the general population. Five and ten-year graft survival were $85 \%$ and $69 \%$ respectively in the most deprived quintile vs. $90 \%$ and $83 \%$ respectively in the least deprived quintile. At any time after transplantation, patients in the most deprived quintile had almost a two-fold higher hazard of graft failure compared with the least deprived quintile, after adjustment for age at renal replacement therapy, duration of dialysis, primary kidney disease, and rural/urban living environment (hazard ratio 1.99; 95\% confidence interval 1.20-3.28). The hazard of graft failure did not differ significantly between girls and boys. Thus, our findings suggest a lower socioeconomic status is independently associated with poor graft outcome in pediatric kidney transplantation.
\end{abstract}

\title{
Keywords
}

Pediatric kidney transplantation, end-stage kidney disease, kidney graft failure, deprivation, French EDI 


\section{Introduction}

Kidney transplantation is recognized as the treatment of choice for end-stage kidney disease (ESKD) in both adults and children. It is therefore critical to take into consideration all the potential determinants of graft failure for both populations in order to optimize transplantation outcome. Social determinants have been shown to be associated with incidence of ESKD, access to transplantation, and kidney graft survival in adults ${ }^{1-7}$, but very few studies investigated the relationship between deprivation and kidney transplant outcome in the pediatric population. Yet, children and adolescents have established specificities with regard to chronic kidney disease and kidney transplantation, as well as to social deprivation. ${ }^{8-10}$ Optimal ESKD care including successful kidney transplantation is critical to guarantee these children to have a normal physical, psychological and social development to integrate into adult life under the best possible conditions. The support and involvement of families are essential for these children and adolescents with a kidney transplant who must follow a specific diet, hydrate regularly and above all, have a rigorous adherence to immunosuppressive therapy. The process of managing diet and medication depends on the understanding of instruction; this ability to understand health-related information is called health literacy. Limited health literacy has been associated with low socioeconomic status. ${ }^{11}$ Thus, taking into account the socioeconomic factors of the family in the pediatric kidney transplantation setting seems even more important. In the United States (US), ethnicity was found to be associated with access to transplantation and kidney transplant outcome in children. ${ }^{12,13}$ This relationship was partly driven by socioeconomic status, assessed by the neighborhood poverty level. In Nicaragua, a lowincome country, researchers found that family income was a major determinant of mortality in pediatric dialysis patients. ${ }^{14}$ However, to our knowledge, no study has been carried out in Europe on the potential impact of social deprivation on kidney graft survival in children. It is questionable whether impact of socioeconomic determinant would be the same in Europe, especially in France where healthcare and social systems greatly differ from those of US or low-income countries.

The objective of this study was to assess the association between social deprivation and graft failure in pediatric kidney transplant recipients in France. 


\section{Results}

\section{Comparison between included and excluded patients}

Among the 1248 children and adolescents who were listed before the age of 18 years and who received a first kidney transplant between January $1^{\text {st }}, 2002$ and December 31 1 st, 2014 , 198 had been excluded because of their reported residential address. Among them, 101 were living abroad or in overseas departments, 7 had an address located at the hospital and 90 lived in metropolitan France but their address was not precise enough to identify the corresponding entity (Figure 1). Characteristics of included and excluded patients were different except for HLA matching and cold ischemia time, which were similar between groups (Table S1 in supplementary materials). Among the relevant differences, patients who were excluded because living abroad or in overseas departments tended to have a longer duration of dialysis (25.1 months vs. 12.3 months), more living donors (31.7\% vs. $12.9 \%)$ but less pre-emptive kidney transplantation (8.9\% vs. $15.6 \%)$ (Table S1 in supplementary materials). Moreover, graft survival tended to be shorter for excluded patients, especially for those without sufficiently precise information on their address (Figure S1, supplementary materials).

\section{Characteristics at transplantation of included patients}

Among the 1050 included patients, about 60\% were males, the median age at transplantation was 13.3 years old (Table 1 ). One third (35\%) had CAKUT as primary disease. Only $23 \%$ benefited from a preemptive transplantation. For non-preemptive transplant recipients, the median duration on dialysis was 12.3 months. The median waiting time between registration on the waiting list and transplantation was 4.7 months. Between 14 and 19\% of patients were distributed in each quintile 1 to 4 of EDI whereas the most deprived quintile 5 comprised almost $37 \%$ of the patients (Table 1 ). Patients from quintile 5 tended to live less in rural area (about 3\% vs. 20 to $36 \%$ in other quintiles), to have a longer duration of dialysis (median of about 20 months vs. 15 to 17 months for quintiles 1 - 3), to start renal replacement therapy more often with hemodialysis than with peritoneal dialysis (more than $60 \%$ vs. 45 to $55 \%$ in other quintiles) and to receive less often a living donor kidney (about $8 \%$ vs. about $20 \%$ in quintiles 1 and 2). Ages at transplantation, primary kidney disease, having any comorbidity, height z-score, waiting time, HLA matching and cold ischemia time were similar between quintiles (Table 1 ). 


\section{Kidney graft survival probability in each quintile of EDI}

Among the 1050 patients, 211 lost their graft within a median follow-up period of 5.9 years (interquartile range 2.9-9.1 years). Among the 211 patients with a graft failure, $180(85.3 \%)$ had (re)dialysis (85.3\%) first, 10 (4.7\%) had retransplantation first and 21 (10\%) died with a functioning graft. Five and 10 -year graft survival were $85 \%$ and $69 \%$ respectively in the most deprived group (quintile 5) vs. $90 \%$ and $83 \%$ respectively in the least deprived group (quintile 1) (Figure 2).

\section{Association between EDI and graft failure}

The hazard of graft failure significantly increased with the quantitative score of EDI after adjustment for age at replacement therapy, duration of dialysis, primary kidney disease and urban/rural living environment $(p=0.01)$ (Figure 3$)$. At any time after transplantation, patients from the most deprived area (quintile 5) had a two-fold higher hazard of graft failure compared to those from the least deprived area (quintile 1) (HR 1.99, 95\% $\mathrm{Cl} 1.20 ; 3.28)$ (Table 2). When patients in the quintile 5 were compared to all other patients (quintile 1-4), the association remained statistically significant (HR $1.54,95 \% \mathrm{Cl} 1.12 ; 2.13$ ). The association between EDI (quintile 5 vs. quintiles $1-4$ ) and the hazard of graft failure did not differ statistically significantly between girls and boys (Table 2 ). In the mediation analysis, the effect of deprivation on the hazard of graft failure was not driven by HLA matching and cold ischemia time or donor type (Table 2). After further adjustment for comorbidities, the hazard ratios for the quintiles of EDI remained of the same magnitude (Table S2), although slightly more significant ( $p=0.01$ versus $p=0.08$ in Table 1$)$. When excluding death from the definition of graft failure, the most deprived patients (quintile 5) had at any time after transplantation, a 57\% increase in hazard of graft failure compared to less deprived patients (quintiles 1-4) (HR 1.57, 95\% Cl 1.13; 2.20). 


\section{Discussion}

Our results suggest that deprivation is more frequent in pediatric ESKD patients than in the general population. Indeed, $37 \%$ of the patients were in the quintile 5 corresponding to the $20 \%$ most deprived areas in France which themselves include about $29 \%$ of the French general population. These patients living in the most deprived area had a substantially lower 10-year graft survival (69\%) than those living in the wealthiest area, quintile 1 (83\%). After adjusting for age at renal replacement therapy, duration of dialysis, context of living environment, and primary kidney disease, patients from quintile 5 had still a significant higher hazard of graft failure which was not likely mediated by HLA matching, donor type or cold ischemia type.

These results are consistent with previous pediatric studies, done in others countries, mostly in the US. Muneeruddin et al. have found in a single center US cohort that socioeconomic status of the family, assessed by income and education levels, had a significant influence on kidney graft survival in children. ${ }^{15}$ Similarly, Patzer et al. have studied the impact of deprivation and ethnicity in pediatric kidney transplantation using large cohorts from the US Renal Data System (USRDS). Overall, in these studies, a higher level of deprivation was associated with a lower access to the transplant waiting list and a shorter kidney graft survival. ${ }^{12,13}$ Conversely, Miller et al. recently studied the correlation between US county-level socioeconomic status and 1-year pediatric kidney transplant outcomes and showed no conclusive evidence of a relationship. ${ }^{16} \mathrm{~A}$ previous study conducted in Australia, found that remoteness had an impact on receiving pre-emptive transplant but no association between socioeconomic status and transplant outcome has been showed. ${ }^{17}$ Moreover, another pediatric study in Nicaragua found a significant association between deprivation and mortality rate among patients on dialysis. ${ }^{14}$ Most of the data are thus consistent across countries, despite different healthcare systems. For example, the French healthcare system fully covers all immunosuppressive drugs ${ }^{18}$, as opposed to the US where Medicare covers for 36 months only for most patients. ${ }^{19}$

More than one third of our patients came from the most deprived areas. Our study thus may suggest that pediatric patients with chronic kidney disease come from the most deprived family. It would be important to confirm this result with further studies investigating whether this is a general pattern for all pediatric patients in France or even for the general population of children since quintile were defined for all ages. Pediatric patients may thus have more health problems prior to ESKD due to lower access to healthcare services, and delayed referral to highly specialized care. We can therefore hypothesize that deprivation has an impact in the earlier stages of chronic kidney disease. According to our results, we can split the population into three groups: patients from quintile 1 , the wealthiest who are also the healthiest; patients from quintile 2, 3 and 4, who have an intermediate risk of graft 
failure; and patients from the quintile 5 who have a significantly higher risk of graft failure than quintile 1 and higher than all quintiles together. This difference in kidney graft survival between the least and the most deprived group may be explained by several reasons. First, this population may have a lower access to healthcare system in general, even for transplantation follow-up, due to the lack of care center in their area inducing higher travel cost because of the distance from home. ${ }^{20,21}$ However, this is unlikely in our study since patients from quintile 5 all live in urban areas contrary to the other EDI quintiles. Secondly, a lower knowledge and understanding of the disease and of its treatment could induce an underestimation of the importance of regular follow-up, clinic appointments, and communication with the healthcare team. Limited health literacy may lead to a decreased trust in care providers and low adherence to treatment, which is an important predictor of poor long-term outcome. ${ }^{11,22,23}$ It is also known that socio-economic conditions, family support and functioning are major contributors to non-adherence. ${ }^{24-26}$

Our study has some strengths and limitations. The REIN renal registry is a comprehensive and validated nationwide registry which includes all pediatric and adult kidney transplant recipients in France. This substantial data source allowed us an adequate statistical power. However, this registry does not collect any individual information on socioeconomic status and ethnicity, both usually associated. Hence, we used an ecological index, the EDI, as a proxy of the individual level of deprivation. The EDI has been validated and successfully compare to other ecological index deprivation ${ }^{27,28}$. It has also already been used in adult nephrology ${ }^{29}$, as well as in cancer ${ }^{30,31}$. However, even if the EDI has been validated and is restricted to a small geographic area (IRIS) a possible ecological bias remains. Indeed, it is possible that individuals have been classified in a certain quintile because they live in the corresponding area while their individual level of deprivation is lower or higher. This potential bias can lead to either an underestimation or an overestimation of the estimated hazard ratios. We also did the strong assumption that the patients never moved from the first address provided at the inscription on the waiting list or more generally tended to stay in the same level of deprivation area. Nevertheless, the EDI presents several advantages. First, it is transposable in time and in many European countries which allows easy comparisons between European data. Secondly, it is a multidimensional indicator which takes into account the material dimension usually associated with objective poverty and the social dimension corresponding to subjective poverty.

For example, while we did not have any individual information on ethnicity in the registry, the EDI accounted for the percentage of people with foreign nationality in the neighborhood. In the 2007 French census, this percentage was higher in Quintile 5 than in the others (11\% vs $2-5 \%)$ and most of 
people with foreign nationality belong to the Quintile 5 (55\% vs $7-18 \%$ in Quintiles 1-4). This multidimensional aspect prevent from an overrepresentation of health domain. ${ }^{32}$

To appropriately capture the effect of deprivation, it was important to adjust for potential confounders in all statistical analyses. In a sensitivity analysis using multiple imputation for missing data, we further adjusted for comorbidities at transplantation and this strengthened the relationship between deprivation and graft failure. We also performed a mediation analysis to take into account the potential mediators in the causal pathway between deprivation and kidney graft failure. For this purpose, we assumed that children and adolescents living in deprived areas had poorer clinical conditions than those from wealthier areas. Thus, physicians might be less demanding on the kidney graft quality in order to provide prompt access to transplantation and limit dialysis exposure. We thus assumed that deprivation might influence indicators of graft quality like HLA matching, cold ischemia time and donor type. Donor type is also a factor which may partly reflect access to care and late referral. However, we did not find that the effect of deprivation on transplant outcome was transmitted through these indicators of graft quality and of access to care. Other mediators such as adherence to treatment may explain the observed association between deprivation and graft failure. However, we could not assess the role of poor adherence to treatment in the relationship between deprivation and graft failure because we were limited by the available data in the REIN registry and adherence or immunosuppressive drugs trough levels were not collected. We also did not have any information on parental health, which yet could act as a potential confounder if parents with poor health are more likely to be deprived and less likely to ensure good adherence to treatments of their child. Another limitation concerns the exclusion of 198 patients because of missing data in EDI. Because these patients had a higher risk of graft failure, we may have underestimated the effect of deprivation if they came from the most deprived area or overestimated it if they came from the least deprived area.

In conclusion, this study is, to our knowledge, the first to investigate the relationship between socioeconomic status and kidney transplant outcome in a European pediatric population. Our results highlight that, despite the French health care system (chronic illness reimbursement, universal medical coverage, welfare payments), children living in the most deprived areas have a higher risk of kidney graft failure. These findings suggest that specific interventions targeted at low socioeconomic status patients are needed to reduce these disparities. These interventions need to take into account the different domains of social determinants to identify the specific needs of the patient. ${ }^{33}$ 


\section{Methods}

\section{Study Design, Setting and Population}

Data were collected from the French Renal Epidemiology and Information Network (REIN), an exhaustive national renal replacement registry. ${ }^{34}$ The present cohort study included all kidney transplant patients who were registered on the French transplant waiting list before the age of 18 years and who received a first kidney transplant between January $1^{\text {st }}, 2002$ and December 31 $1^{\text {st }}, 2014$.

\section{Event of interest}

The primary event of interest was kidney graft failure defined as the first event occurring among: (return to) dialysis, retransplantation, or death. Note that (return to) dialysis for a short period of time ( $<45$ days) was not considered as a graft failure. The time axis was the time elapsed from transplant to graft failure or to administrative censoring on December $31^{\text {st }}, 2015$.

\section{$\underline{\text { Social deprivation assessment }}$}

Because of a lack of individual socioeconomic status in the REIN registry, we used the French version of a validated ecological index of deprivation, the European Deprivation Index (EDI) ${ }^{32}$ as a proxy of the individual level of social deprivation. The EDI has been derived from both 2007 French population census data and a 2006 European survey specifically designed to study deprivation (European Union - Statistics on Income and Living) $)^{35}$, which took into account individuals' cultural and social environments. We included patients during the period 2002 - 2014, thus EDI was calculated approximatively at the mid-period of inclusion.

More specifically, the EDI is a continuous score, which is the result of a linear combination of 10 variables on the percentage, in the neighborhood, of :1) overcrowded housing, 2) housing with no access to a system of central or electric heating, 3) household non-owners, 4) unemployed people, 5) persons with foreign nationality, 6) household without access to a car, 7) unskilled or farm workers, 8) households with six or more persons, 9) persons with less than the first stage of secondary education level and 10) single-parent households ${ }^{32}$.

The neighborhood was defined by the municipality or when the municipality was too large, by the smallest French geographical unit, called IRIS. France is composed of about 50200 entities with 16100 IRIS. Each IRIS has homogenous habitat type and is delineated by main cuttings of urban landscape, made by a population ranging from 1800 to 5000 inhabitants.

In this study, the observed value for the 10 variables of EDI was based for each entity on the French 2007 census data. For each patient, we assigned the entity corresponding to the residential address 
of the children which was collected at the time of registration on the waiting list. Patients living abroad or in French overseas departments, patients without sufficiently precise address to identify the corresponding entity, or with their reported address at the hospital were excluded from the analysis.

We used the continuous version of the EDI and its quintiles to categorize each patient into each five groups of deprivation, from the least deprived (quintile 1) to the most deprived (quintile 5). The quintiles were not derived those from our own sample, but from all the IRIS of the whole 2007 French census population.

\section{Potential confounders}

Potential confounders were identified from the literature and their hypothetical relations with deprivation and graft failure were graphically summarized in a causal diagram (Figure S2 in supplementary materials). More specifically, potential confounders were age at initiation of renal replacement therapy (in years), duration of dialysis (in months), context of the living environment (urban vs. rural), and primary kidney disease (congenital anomalies of the kidney and urinary tract (CAKUT), hereditary nephropathy, glomerular and vascular disease, and other/unknown).

\section{Statistical analysis}

We first compared the characteristics and the probabilities to survive with a functioning graft of included and excluded patients and then between the groups of included patients defined by the quintiles of EDI. Kidney graft survival probabilities were estimated using Kaplan Meier estimator and compared with the log rank test.

The adjusted association between deprivation and graft failure was first estimated using either the continuous score of EDI or its quintiles in a Cox model adjusted for all potential confounders. To account for potential nonlinear effects of quantitative variables (continuous EDI, age at replacement therapy, dialysis duration), we used penalized splines with four degrees of freedom (pspline function in the Coxph function of R). ${ }^{36,37}$ We then used a binary indicator of EDI representing the most deprived children (quintile 5) vs. all the others (quintiles 1-4), and evaluate whether its adjusted association with graft failure differed in boys and girls using an interaction term between EDI and sex. We accounted for the correlation between children living in the same entity using a sandwich estimator for the variances. ${ }^{38}$ The proportional hazard assumption was checked using Schoenfeld residuals.

To further assess to which extend the effect of deprivation could partly be explained by the quality of graft, we performed mediation analyses. ${ }^{39-41}$ More specifically, we assumed that deprived children 
were more likely to have poor health, and that their physicians may for this reason be less willing to wait for the optimal graft, which in turn may impact graft failure (Figure S2 in supplementary materials). The mediators were the number of HLA-A-B-DR mismatches $(0-2,3-6)$ and either donor type (living vs. dead) or cold ischemia time ( $<$ vs. $\geq 955$ minutes). Donor type and cold ischemia time were not included in the same mediation analysis because inherently strongly correlated. Both mediation analyses were performed using a counterfactual approach for survival outcome with multiple mediators. ${ }^{41}$ More specifically, we used separate logistic regression models for each mediator and Cox models for graft failure, and we derived the direct and indirect effects of deprivation as described in Huang and Yang. ${ }^{41}$

\section{Sensitivity analyses}

In a first sensitivity analysis, we further adjusted for having any comorbidity (yes/no) among visual disability or blindness, hearing disability, motor disability, psychomotor disability, behavior disorder. These comorbidities usually correspond to congenital disorders, therefore present before transplantation. Because data on these comorbidities were missing for almost half of the patients, we used multiple imputation (R package MICE). In a second sensitivity analysis, we used a causespecific Cox model censoring at death to evaluate the adjusted association between EDI and graft failure excluding death. ${ }^{42}$

\section{Supplementary Material}

Figure S1. Survival with a functioning graft for included and excluded patients estimated using the Kaplan-Meir estimator and compared with the log rank test $(p=0.0004)$. Data from the French renal registry, 2002-2015 ( $n=1248)$

Figure S2. Assumed causal relationships between deprivation (measured by EDI) and graft failure, and its potential confounders, mediators, and effect modifiers

Table S1. Population characteristics among included and excluded patients of the study in France (data REIN, 2002-2014)*

Table S2. Association between deprivation and graft failure in young kidney transplant patients in France (Data from the French renal registry, 2002-2014)

Supplementary information is available at Kidney International's website

\section{Disclosure}

All the authors declared no competing interests. 


\section{References}

1. Stephens MR, Evans M, Ilham MA, et al. The influence of socioeconomic deprivation on outcomes following renal transplantation in the United kingdom. Am J Transplant. 2010;10(7):1605-1612.

2. Akrawi DS, Li X, Sundquist J, et al. End stage renal disease risk and neighbourhood deprivation: a nationwide cohort study in Sweden. Eur J Intern Med. 2014;25(9):853-859.

3. Goldfarb-Rumyantzev AS, Koford JK, Baird BC, et al. Role of socioeconomic status in kidney transplant outcome. Clin J Am Soc Nephrol. 2006;1(2):313-322.

4. Schold JD, Flechner SM, Poggio ED, et al. Residential Area Life Expectancy: Association With Outcomes and Processes of Care for Patients With ESRD in the United States. Am J Kidney Dis. 2018.

5. Fored CM, Ejerblad E, Fryzek JP, et al. Socio-economic status and chronic renal failure: a population-based case-control study in Sweden. Nephrol Dial Transplant. 2003;18(1):82-88.

6. Kihal-Talantikite W, Deguen S, Padilla C, et al. Spatial distribution of end-stage renal disease (ESRD) and social inequalities in mixed urban and rural areas: a study in the Bretagne administrative region of France. Clin Kidney J. 2015;8(1):7-13.

7. Kihal-Talantikite W, Vigneau C, Deguen S, et al. Influence of Socio-Economic Inequalities on Access to Renal Transplantation and Survival of Patients with End-Stage Renal Disease. PLoS One. 2016;11(4):e0153431.

8. Bertram JF, Goldstein SL, Pape L, et al. Kidney disease in children: latest advances and remaining challenges. Nat Rev Nephrol. 2016;12(3):182-191.

9. Brophy PD, Shoham DA, Group CKDLC, et al. Early-life course socioeconomic factors and chronic kidney disease. Adv Chronic Kidney Dis. 2015;22(1):16-23.

10. Freeman MA, Myaskovsky L. An overview of disparities and interventions in pediatric kidney transplantation worldwide. Pediatr Nephrol. 2015;30(7):1077-1086.

11. Taylor DM, Fraser S, Dudley C, et al. Health literacy and patient outcomes in chronic kidney disease: a systematic review. Nephrol Dial Transplant. 2017.

12. Patzer RE, Amaral $\mathrm{S}$, Klein $\mathrm{M}$, et al. Racial disparities in pediatric access to kidney transplantation: does socioeconomic status play a role? Am J Transplant. 2012;12(2):369378.

13. Patzer RE, Mohan S, Kutner N, et al. Racial and ethnic disparities in pediatric renal allograft survival in the United States. Kidney Int. 2015;87(3):584-592.

14. Montini G, Edefonti A, Galan YS, et al. Non-Medical Risk Factors as Avoidable Determinants of Excess Mortality in Children with Chronic Kidney Disease. A Prospective Cohort Study in Nicaragua, a Model Low Income Country. PLoS One. 2016;11(5):e0153963.

15. Muneeruddin S, Chandar J, Abitbol CL, et al. Two decades of pediatric kidney transplantation in a multi-ethnic cohort. Pediatr Transplant. 2010;14(5):667-674.

16. Miller R, Akateh $\mathrm{C}$, Thompson N, et al. County socioeconomic characteristics and pediatric renal transplantation outcomes. Pediatr Nephrol. 2018.

17. Francis $\mathrm{A}$, Didsbury $\mathrm{M}$, Lim $\mathrm{WH}$, et al. The impact of socioeconomic status and geographic remoteness on access to pre-emptive kidney transplantation and transplant outcomes among children. Pediatr Nephrol. 2016;31(6):1011-1019.

18. Steffen M. Universalism, Responsiveness, Sustainability--Regulating the French Health Care System. N Engl J Med. 2016;374(5):401-405.

19. Tanriover B, Stone PW, Mohan S, et al. Future of Medicare immunosuppressive drug coverage for kidney transplant recipients in the United States. Clin J Am Soc Nephrol. 2013;8(7):1258-1266.

20. Garcia-Garcia G, Jha V, Tao Li PK, et al. Chronic kidney disease (CKD) in disadvantaged populations. Clin Kidney J. 2015;8(1):3-6. 
21. Crews DC, Charles RF, Evans MK, et al. Poverty, race, and CKD in a racially and socioeconomically diverse urban population. Am J Kidney Dis. 2010;55(6):992-1000.

22. Dobbels F, Ruppar T, De Geest $\mathrm{S}$, et al. Adherence to the immunosuppressive regimen in pediatric kidney transplant recipients: a systematic review. Pediatr Transplant. 2010;14(5):603-613.

23. Nankivell BJ, Chapman JR. Chronic allograft nephropathy: current concepts and future directions. Transplantation. 2006;81(5):643-654.

24. Nevins TE, Nickerson PW, Dew MA. Understanding Medication Nonadherence after Kidney Transplant. J Am Soc Nephrol. 2017;28(8):2290-2301.

25. Steinberg $E A$, Moss $M$, Buchanan $C L$, et al. Adherence in pediatric kidney transplant recipients: solutions for the system. Pediatr Nephrol. 2018;33(3):361-372.

26. Killian MO, Schuman DL, Mayersohn GS, Triplett KN. Psychosocial predictors of medication non-adherence in pediatric organ transplantation: A systematic review. Pediatr Transplant. 2018:e13188.

27. Bryere J, Dejardin O, Bouvier V, et al. Socioeconomic environment and cancer incidence: a French population-based study in Normandy. BMC Cancer. 2014;14:87.

28. Bryere J, Pornet C, Copin N, et al. Assessment of the ecological bias of seven aggregate social deprivation indices. BMC Public Health. 2017;17(1):86.

29. Chatelet V, Bayat-Makoei S, Vigneau C, et al. Renal transplantation outcome and social deprivation in the French healthcare system: a cohort study using the European Deprivation Index. Transpl Int. 2018;31(10):1089-1098.

30. Menvielle G, Kulhanova I, Bryere J, et al. Tobacco-attributable burden of cancer according to socioeconomic position in France. Int J Cancer. 2018;143(3):478-485.

31. Moriceau G, Bourmaud A, Tinquaut $F$, et al. Social inequalities and cancer: can the European deprivation index predict patients' difficulties in health care access? a pilot study. Oncotarget. 2016;7(1):1055-1065.

32. Pornet C, Delpierre C, Dejardin O, et al. Construction of an adaptable European transnational ecological deprivation index: the French version. I Epidemiol Community Health. 2012;66(11):982-989.

33. Sereni $F$, Edefonti $A$, Lepore $M$, et al. Social and economic determinants of pediatric health inequalities: the model of chronic kidney disease. Pediatr Res. 2016;79(1-2):159-168.

34. Couchoud $C$, Stengel $B$, Landais $P$, et al. The renal epidemiology and information network (REIN): a new registry for end-stage renal disease in France. Nephrol Dial Transplant. 2006;21(2):411-418.

35. Arora VS, Karanikolos M, Clair A, et al. Data Resource Profile: The European Union Statistics on Income and Living Conditions (EU-SILC). Int J Epidemiol. 2015;44(2):451-461.

36. Leffondre K, Jager KJ, Boucquemont J, et al. Representation of exposures in regression analysis and interpretation of regression coefficients: basic concepts and pitfalls. Nephrol Dial Transplant. 2014;29(10):1806-1814.

37. Eilers PHC MB. Flexible smoothing with B-splines and penalties. Statistical Science. 1996;11(2):89-121.

38. Paul SR, Zaihra T. Interval estimation of risk difference for data sampled from clusters. Stat Med. 2008;27(21):4207-4220.

39. VanderWeele TJ, Vansteelandt S. Mediation Analysis with Multiple Mediators. Epidemiol Methods. 2014;2(1):95-115.

40. Valeri L, Vanderweele TJ. Mediation analysis allowing for exposure-mediator interactions and causal interpretation: theoretical assumptions and implementation with SAS and SPSS macros. Psychol Methods. 2013;18(2):137-150.

41. Huang YT, Yang HI. Causal Mediation Analysis of Survival Outcome with Multiple Mediators. Epidemiology. 2017;28(3):370-378.

42. Noordzij M, Leffondre K, van Stralen KJ, et al. When do we need competing risks methods for survival analysis in nephrology? Nephrol Dial Transplant. 2013;28(11):2670-2677. 


\section{Acknowledgments}

BD was supported by an MSc fellowship from the CIC-EC 1401 and a doctoral award from the French Public Health Doctoral Network. 


\section{Figures and Tables}

Figure 1. Flow chart describing the sample selection, French renal registry 2002-2014

Figure 2. Survival with a functioning graft according to quintile of deprivation estimated using the Kaplan-Meir estimator and compared with the log rank test $(p=0.113)$. Data from the French renal registry, 2002-2014 $(n=1050)$

Figure 3. Association between deprivation estimated by EDI and kidney graft failure including death in young kidney transplant patients in France adjusted for age at renal replacement therapy, duration of dialysis, context of their living environment (urban versus rural) and primary kidney disease (CAKUT, hereditary nephropathy, glomerular/vascular disease, other/unknown). Data from the French renal registry, 2002-2014 $(n=1050)$. All quantitative variables were modelled using $p$-spline with four degrees of freedom in the Cox model

Table 1. Population characteristics at transplantation according to deprivation quintiles (quintile 5 most deprived) of 1050 young kidney transplant patients in France (data from the French renal registry, 2002-2014)

Table 2. Association between deprivation and graft failure in young kidney transplant patients in France (Data from the French renal registry, 2002-2014) 
Table 1. Population characteristics at transplantation according to deprivation quintiles (Quintile 5 most deprived) of 1050 young kidney transplant patients in France (data REIN, 2002-2014).

\begin{tabular}{|c|c|c|c|c|c|c|c|c|c|c|c|c|}
\hline \multirow[b]{2}{*}{ Characteristics } & \multicolumn{2}{|c|}{$\begin{array}{c}\text { All subjects } \\
\mathrm{n}=1050\end{array}$} & \multicolumn{2}{|c|}{$\begin{array}{c}\text { Quintile 1 } \\
\mathrm{n}=152(14.5 \%)\end{array}$} & \multicolumn{2}{|c|}{$\begin{array}{c}\text { Quintile } 2 \\
\mathrm{n}=166(15.8 \%)\end{array}$} & \multicolumn{2}{|c|}{$\begin{array}{c}\text { Quintile } 3 \\
\mathrm{n}=152(14.5 \%)\end{array}$} & \multicolumn{2}{|c|}{$\begin{array}{c}\text { Quintile } 4 \\
\mathrm{n}=196(18.6 \%)\end{array}$} & \multicolumn{2}{|c|}{$\begin{array}{c}\text { Quintile } 5 \\
\mathrm{n}=384(36.6 \%)\end{array}$} \\
\hline & $\mathrm{n}(\%)$ & Median [IO] & $n(\%)$ & Median [IQ] & $n(\%)$ & Median [IQ] & $n(\%)$ & Median [IQ] & $n(\%)$ & Median [IQ] & $\mathrm{n}(\%)$ & Median [IQ] \\
\hline \multicolumn{13}{|l|}{ Recipients } \\
\hline Male & $624(59.4)$ & & $96(63.2)$ & & $102(61.4)$ & & $87(57.2)$ & & $120(61.2)$ & & $219(57.0)$ & \\
\hline $\begin{array}{l}\text { Age at transplantation } \\
\text { (years) }\end{array}$ & 1050 & $\begin{array}{c}13.3 \\
{[7.7 ; 16.4]}\end{array}$ & 152 & $\begin{array}{c}13.0 \\
{[6.2 ; 16.3]}\end{array}$ & 166 & $\begin{array}{c}13.2 \\
{[7.7 ; 16.4]}\end{array}$ & 152 & $\begin{array}{c}12.8 \\
{[7.4 ; 16.0]}\end{array}$ & 196 & $\begin{array}{c}13.9 \\
{[9.1 ; 17.1]}\end{array}$ & 384 & $\begin{array}{c}13.4 \\
{[8.1 ; 16.2]}\end{array}$ \\
\hline $\begin{array}{l}\text { Context of living (rural) } \\
\text { (missing }=72 \text { ) }\end{array}$ & $203(20.8)$ & & $42(28.2)$ & & $58(36.2)$ & & $53(36.8)$ & & $40(22.2)$ & & $10(2.9)$ & \\
\hline \multicolumn{13}{|l|}{ Primary disease } \\
\hline CAKUT & $368(35.1)$ & & $60(39.5)$ & & $56(33.7)$ & & 53 (34.9) & & $80(40.8)$ & & $119(31.0)$ & \\
\hline Hereditary nephropathy & $206(19.6)$ & & $32(21.1)$ & & $32(19.3)$ & & 29 (19.1) & & $34(17.3)$ & & $79(20.6)$ & \\
\hline $\begin{array}{l}\text { Glomerular/vascular } \\
\text { disease }\end{array}$ & $272(25.9)$ & & $35(23.0)$ & & 44 (26.5) & & $31(20.4)$ & & $47(24.0)$ & & 115 (29.9) & \\
\hline Other/Unknown & 204 (19.4) & & $25(16.4)$ & & $34(20.5)$ & & $39(25.7)$ & & 35 (17.9) & & $71(18.5)$ & \\
\hline $\begin{array}{l}\text { Any comorbidity } \\
\text { (missing = 564) }\end{array}$ & $102(21.0)$ & & $13(20.0)$ & & 13 (19.1) & & $16(25.4)$ & & $20(25.0)$ & & $40(19.1)$ & \\
\hline $\begin{array}{l}\text { Height Z-score } \\
\text { (missing = 503) }\end{array}$ & 547 & $\begin{array}{c}-0.65 \\
{[-1.7 ; 0.4]}\end{array}$ & 74 & $\begin{array}{c}-0.56 \\
{[-1.4 ; 0.3]}\end{array}$ & 82 & $\begin{array}{c}-0.53 \\
{[-1.3 ; 0.1]}\end{array}$ & 72 & $\begin{array}{c}-0.85 \\
{[-1.9 ; 0.5]}\end{array}$ & 102 & $\begin{array}{c}-0.64 \\
{[-1.8 ; 0.4]}\end{array}$ & 217 & $\begin{array}{c}-0.72 \\
{[-1.8 ; 0.5]}\end{array}$ \\
\hline $\begin{array}{l}\text { Waiting time on } \\
\text { transplantation list } \\
\text { (months) }\end{array}$ & 1050 & $\begin{array}{c}4.7 \\
{[2.0 ; 11.0]}\end{array}$ & 152 & $\begin{array}{c}4.5 \\
{[1.5 ; 10.6]}\end{array}$ & 166 & $\begin{array}{c}4.6 \\
{[2.0 ; 9.5]}\end{array}$ & 152 & $\begin{array}{c}4.5 \\
{[2.1 ; 11.2]}\end{array}$ & 196 & $\begin{array}{c}4.6 \\
{[1.9 ; 12.6]}\end{array}$ & 384 & $\begin{array}{c}5.2 \\
{[2.2 ; 11.2]}\end{array}$ \\
\hline $\begin{array}{l}\text { Pre-emptive } \\
\text { transplantation }\end{array}$ & $242(23.0)$ & & 47 (30.9) & & $42(25.3)$ & & $46(30.3)$ & & 47 (23.9) & & $60(15.6)$ & \\
\hline $\begin{array}{l}\text { Dialysis duration } \\
\text { (months) }\end{array}$ & 808 & $\begin{array}{c}12.3 \\
{[6.3 ; 23.7]}\end{array}$ & 105 & $\begin{array}{c}10.1 \\
{[4.6 ; 16.9]}\end{array}$ & 124 & $\begin{array}{c}12.7 \\
{[6.6 ; 23.2]}\end{array}$ & 106 & $\begin{array}{c}11.7 \\
{[6.6 ; 23.2]}\end{array}$ & 149 & $\begin{array}{c}13.2 \\
{[7.3 ; 26.7]}\end{array}$ & 324 & $\begin{array}{c}12.5 \\
{[6.3 ; 24.3]}\end{array}$ \\
\hline Age at dialysis (years) & 808 & $\begin{array}{c}12.1 \\
{[5.7 ; 15.4]}\end{array}$ & 105 & $\begin{array}{c}11.7 \\
{[3.8 ; 11.7]}\end{array}$ & 124 & $\begin{array}{c}11.9 \\
{[5.0 ; 15.7]}\end{array}$ & 106 & $\begin{array}{c}11.0 \\
{[4.8 ; 15.0]}\end{array}$ & 149 & $\begin{array}{c}13.0 \\
{[7.6 ; 15.6]}\end{array}$ & 324 & $\begin{array}{c}12.2 \\
{[6.0 ; 15.0]}\end{array}$ \\
\hline \multicolumn{13}{|l|}{$\begin{array}{l}\text { Type of dialysis } \\
\text { (missing = 8) }\end{array}$} \\
\hline Hemodialysis & $582(72.8)$ & & $71(67.6)$ & & $93(75.0)$ & & $71(67.6)$ & & $103(70.1)$ & & $244(76.5)$ & \\
\hline Peritoneal dialysis & $218(27.2)$ & & $34(32.4)$ & & $31(25)$ & & $34(32.4)$ & & 44 (29.9) & & $75(23.5)$ & \\
\hline \multicolumn{13}{|l|}{ Donor } \\
\hline Living donor & $135(12.1)$ & & $32(21.1)$ & & $32(19.3)$ & & $14(9.2)$ & & $28(14.3)$ & & $29(7.6)$ & \\
\hline $\begin{array}{l}\text { Age (years) } \\
\text { (missing = 135) }\end{array}$ & 915 & $\begin{array}{c}15.0 \\
{[11.0 ; 18.0]}\end{array}$ & 120 & $\begin{array}{c}15.0 \\
{[11.0 ; 19.0]}\end{array}$ & 134 & $\begin{array}{c}14.0 \\
{[11.0 ; 18.0]}\end{array}$ & 138 & $\begin{array}{c}15.0 \\
{[11.3 ; 18.0]}\end{array}$ & 168 & $\begin{array}{c}15.0 \\
{[10.8 ; 20.0]}\end{array}$ & 355 & $\begin{array}{c}15.0 \\
{[11.0 ; 18.5]}\end{array}$ \\
\hline
\end{tabular}




\begin{tabular}{|c|c|c|c|c|c|c|c|c|c|c|c|c|}
\hline Transplantation & & & & & & & & & & & & \\
\hline \multicolumn{13}{|l|}{$\begin{array}{l}\text { HLA mismatching } \\
\text { (missing = 1) }\end{array}$} \\
\hline $0-2$ & $200(19.1)$ & & $34(22.4)$ & & 39 (23.5) & & $26(17.1)$ & & 33 (16.9) & & 68 (17.7) & \\
\hline $3-4$ & $708(67.5)$ & & $\begin{array}{c}104 \\
(68.4)\end{array}$ & & $106(63.9)$ & & $98(64.5)$ & & $134(68.7)$ & & $266(69.3)$ & \\
\hline $5-6$ & $141(13.4)$ & & $14(9.2)$ & & $21(12.7)$ & & $28(18.4)$ & & $28(14.4)$ & & $50(13.0)$ & \\
\hline $\begin{array}{l}\text { Cold ischemia time } \\
\text { (hours) }(\text { missing }=26)\end{array}$ & 1024 & $\begin{array}{c}15.9 \\
{[12 ; 20]}\end{array}$ & 148 & $\begin{array}{c}14.7 \\
{[10 ; 19]}\end{array}$ & 162 & $\begin{array}{c}15.9 \\
{[10.8 ; 20.1]}\end{array}$ & 149 & $\begin{array}{c}15.1 \\
{[12.0 ; 20.3]}\end{array}$ & 190 & $\begin{array}{c}16.0 \\
{[12.1 ; 19.0]}\end{array}$ & 375 & $\begin{array}{c}16.7 \\
{[13.3 ; 20.1]}\end{array}$ \\
\hline
\end{tabular}


Table 2. Association between deprivation and graft failure in young kidney transplant patients in France (Data from the French renal registry, 2002-2014).

\begin{tabular}{|c|c|c|c|}
\hline & $\mathrm{HR}^{*}$ & $95 \% \mathrm{Cl}$ & $\mathrm{p}$-value \\
\hline \multicolumn{4}{|l|}{ EDI quintiles $(n=978)$} \\
\hline Q1 (least deprived) & $\operatorname{Ref}$ & & 0.08 \\
\hline Q2 & 1.56 & {$[0.88 ; 2.76]$} & \\
\hline Q3 & 1.55 & {$[0.87 ; 2.74]$} & \\
\hline Q4 & 1.47 & {$[0.85 ; 2.54]$} & \\
\hline Q5 (most deprived) & 1.99 & {$[1.20 ; 3.28]$} & \\
\hline EDI binary (Q5 vs Q1-Q4) $(n=952)$ & 1.54 & {$[1.12 ; 2.13]$} & 0.01 \\
\hline \multicolumn{4}{|l|}{ Effect modification by sex } \\
\hline Interaction term & & & 0.55 \\
\hline Girls & 1.70 & {$[0.63 ; 4.57]$} & 0.63 \\
\hline Boys & 1.42 & {$[0.95 ; 2.12]$} & 0.08 \\
\hline \multicolumn{4}{|l|}{ Mediation analysis } \\
\hline \multicolumn{4}{|l|}{ Mediated by HLA matching** and donor type } \\
\hline Direct effect of EDI & 1.48 & {$[1.07 ; 2.04]$} & 0.02 \\
\hline Indirect effect through HLA matching & 1.00 & {$[0.83 ; 1.21]$} & 0.98 \\
\hline Indirect effect through donor type & 1.03 & {$[0.51 ; 2.16]$} & 0.84 \\
\hline \multicolumn{4}{|l|}{ Mediated by HLA matching** and cold ischemia time ${ }^{* * *}$} \\
\hline Direct effect of EDI & 1.48 & {$[1.07 ; 2.04]$} & 0.01 \\
\hline Indirect effect through HLA matching & 1.01 & {$[0.89 ; 1.18]$} & 0.65 \\
\hline Indirect effect through cold ischemia time & 1.00 & {$[0.88 ; 1.14]$} & 0.91 \\
\hline
\end{tabular}

HR: Hazard ratio; $\mathrm{Cl}$ 95\%: 95\% confidence interval; EDI: European deprivation index

*Adjusted for age at replacement therapy (spline), dialysis duration (pspline), context of living environment (rural/urban) and primary kidney disease (four categories)

** Two categories ([0-2]; [3-6])

$* * *$ Threshold at median (=954 days) 
1248 individuals listed before 18 years of age on the waiting list for a kidney graft

Missing data on exposure variables:

198 excluded patients because of unavailable IRIS

- Foreigners or living in overseas departments (101)

1050 sujects for the principal Hospitals (7)

- $\quad$ Living in metropolitan France (90) analysis

Missing data on adjustment variables:

- context of their living environment (72)

978 subjects for the adjusted analysis

Missing data on mediation variables cold ischemia time (25)

HLA matching and cold ischemia time (1)

952 subjects for the mediation analysis

Figure 1. Flow chart describing the sample selection, French renal registry 2002-2014. 


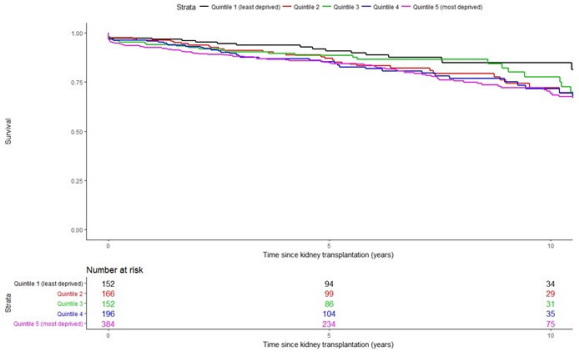

Figure 2. Survival with a functioning graft according to quintile of deprivation estimated using the Kaplan-Meir estimator and compared with the log rank test $(p=0.113)$. Data from the French renal registry, 2002-2014 ( $n=1050)$. 


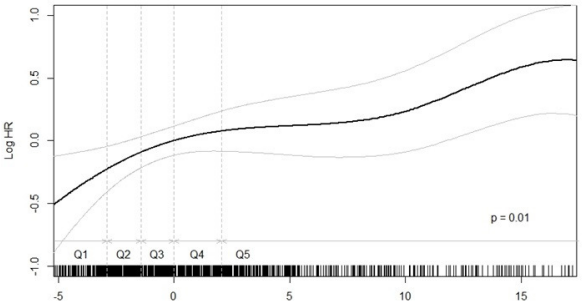

$\mathrm{EDI}$

Figure 3. Association between deprivation estimated by EDI and kidney graft failure including death in young kidney transplant patients in France adjusted for age at renal replacement therapy, duration of dialysis, context of their living environment (urban versus rural) and primary kidney disease (CAKUT, hereditary nephropathy, glomerular/vascular disease, other/unknown). Data from the French renal registry, 2002-2014 ( $n=1050)$. All quantitative variables were modelled using $p$-spline with four degrees of freedom in the Cox model. 


\section{Social deprivation is associated with poor kidney transplantation}

outcome in children.

\section{Population}

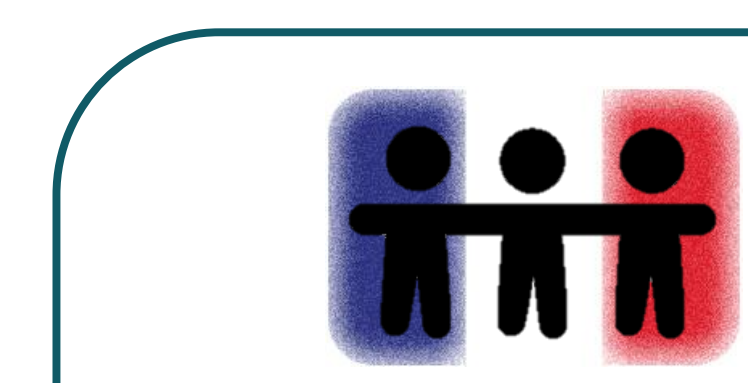

$$
\mathrm{n}=\mathbf{1 0 5 0}
$$

Pediatric Transplant Recipients

- Listed before 18 years

- $59 \%$ males

- $23 \%$ preemptive transplant

- Median age at transplant 13.2 years

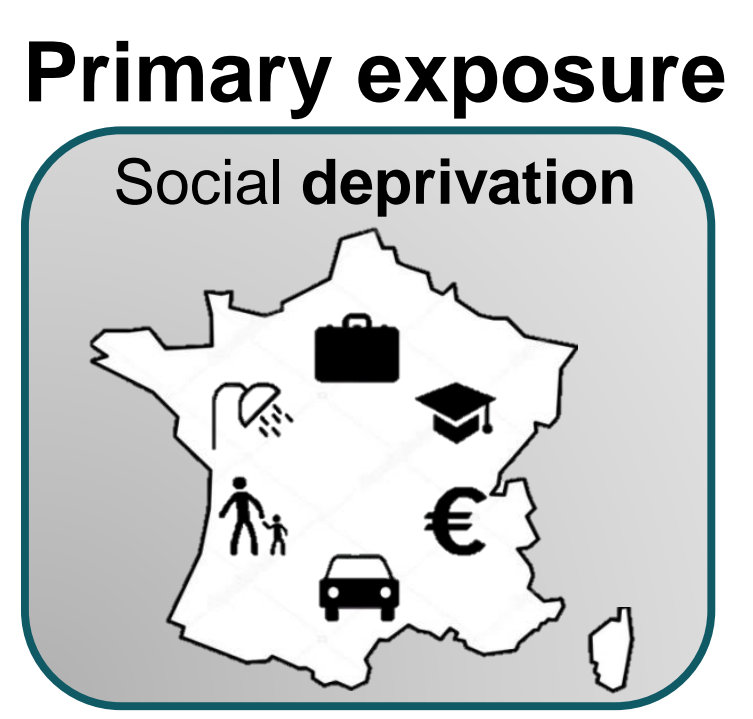

Primary outcome

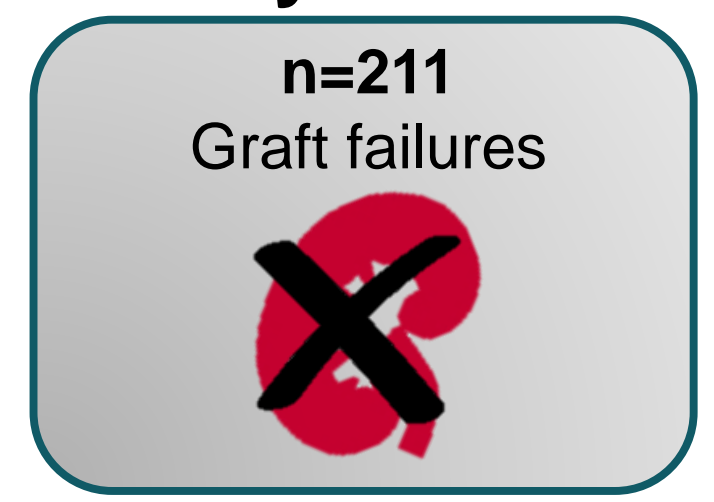

\section{Results}

Risk for least
Risk for most deprived 2-fold higher hazard of graft failure for most vs. least deprived children

\section{CONCLUSION:}

Social deprivation is independently associated with poor graft outcome in pediatric kidney transplantation 